\title{
Laser Surface Melting and Strengthening Magnesium Alloy far from Equilibrium
}

\author{
Ge Yaqiong ${ }^{1,2}$, Wang Wenxian ${ }^{1,3}$, Guo Su ${ }^{1}, \quad$ Cui Zeqin ${ }^{1,3}$ \\ ${ }^{1}$ Taiyuan University of Technology, Taiyuan 030024, China; ${ }^{2}$ Taiyuan University of Science and Technology, Taiyuan 030024, China; ${ }^{3}$ Key \\ Laboratory of Interface Science and Engineering in Advanced Materials, Ministry of Education, Taiyuan 030024, China
}

\begin{abstract}
In order to obtain extremely rapid solidification structure far from equilibrium, the surface of AZ31B magnesium alloy was melted by $\mathrm{CO}_{2}$ laser, while the samples were extremely rapidly cooled in liquid nitrogen. The microstructure, the performance and the strengthening mechanism of the laser melted layer were investigated. The results show that grains of the melted layer are highly refined and the grain size is nearly uniform. The melted layer contains $\alpha$ - $\mathrm{Mg}$ and $\beta$ - $\mathrm{Mg}_{17} \mathrm{Al}_{12}, b$ but $\beta$ - $\mathrm{Mg}_{17} \mathrm{Al}_{12}$ which distributes along the grain boundary is few. Because of strengthening mechanisms of fine grains, super solid solution and dislocation, microhardness HV of the melted layer is up to $1400 \mathrm{MPa}$. Wear loss of the melted sample cooled in liquid nitrogen is about $50 \%$ less than that of the untreated sample and the melted sample cooled in air, and wear resistance of the melted layer is improved obviously. Impacting fracture morphology indicates that there is a trace of plastic deformation, thus, improving plasticity and ductility.
\end{abstract}

Key words: magnesium alloy; laser melting; nonequilibrium; microstructure; performance

Owing to the prominent issues of environment and energy, the importance of new materials development has been widely recognized. Magnesium and its alloys are one of the most important strategic resources in the 21 st century for their excellent properties. So magnesium and its alloys have been developed rapidly in recent years ${ }^{[1-3]}$.

Although magnesium alloys have many advantages such as low density, high specific strength and rigidity, unfortunately, their surface hardness, plasticity and wear resistance are poor ${ }^{[4]}$. Laser surface melting is one of the most active researching methods in surface engineering, which can improve the performance of materials' surface ${ }^{[5]}$. And the improvement of the performance mostly depends on the rapid solidification structure acquired by laser surface treatment.

Conventional laser surface treating and cooling process was in air, so the surface's properties of magnesium alloys carried out by this technique were not perfect. The cooling and solidifying rate of laser surface treating on magnesium alloys should be further improved through reasonable design, and extremely rapid solidification structure far from equilibrium also could be obtained, so magnesium alloys with high performance could be obtained. The extremely rapid solidification structure, including the solid solubility, nonequilibrium crystallization, and microstructure refinement and so on, would be very different from the structure obtained by a conventional laser treatment ${ }^{[6,7]}$.

Laser surface treating on magnesium alloys was only studied in laboratory and of no practical application. Therefore, it is very essential to further study the surface modification technology of magnesium alloys. Above all, there are few researches on the extremely rapid solidification structure and performance of magnesium alloys by laser surface treating under extremely cooling conditions. In the present study the surface of magnesium alloy was heated by laser; meanwhile, the samples were extremely rapidly cooled in liquid nitrogen. The extremely rapid solidification structure and the formation mechanism

Received date: August 13, 2015

Foundation item: National Natural Science Foundation of China (51075293); Research Project Supported by Shanxi Scholarship Council of China (2013-029)

Corresponding author: Wang Wenxian, Ph. D., Professor, College of Materials Science and Engineering, Taiyuan University of Technology, Taiyuan 030024, P. R. China, Tel: 0086-351-6010076, E-mail: wangwenxian@tyut.edu.cn

Copyright (C) 2016, Northwest Institute for Nonferrous Metal Research. Published by Elsevier BV. All rights reserved. 
far from equilibrium were studied, and the influence of the microstructure on microhardness, wear resistance and plasticity of the magnesium alloy's surface was also discussed in detail.

\section{Experiment}

A hot-rolling AZ31B alloy was used as the substrate with the thickness of $10 \mathrm{~mm}$. The chemical composition (wt\%) of the substrate is listed in Table 1.

Before experimenting, in order to increase the energy absorbed by the substrate from $\mathrm{CO}_{2}$ laser, the sample was grit blasted with brown corundum for wiping off the oxide and greasy dirt on the surface. Then the sample was washed by acetone, aired dry, and sprayed with absorbing material which was designed specially. After a second-time airing dry, the specimen was placed in a special container filled with liquid nitrogen with the temperature of $-196{ }^{\circ} \mathrm{C}$, and the back of the specimen was immersed into liquid nitrogen while the front of the specimen was exposed to the air. Laser surface melting was carried out with a continuous wave $\mathrm{CO}_{2}$ laser, and when laser melted the pretreated magnesium alloy under extremely cooling circumstance, argon gas was used to protect molten pool. Fig.1 is a schematic diagram for the process. During the experiment, the protective gas flow rate was $15 \mathrm{~L} / \mathrm{min}$, the spot diameter was $3 \mathrm{~mm}$, and other parameters were constants. The laser energy density was changed, meaning that the laser power and the scanning speed were changed. A part of the process parameters are listed in Table 2. When the laser output power was $3000 \mathrm{~W}$ and the scanning speed was 240 $\mathrm{mm} / \mathrm{min}$, the surface appearance of the melted layer was better, and the process was stable with little spatter. So, the sample with the technique and these parameters was analyzed in the study.

Table 1 Chemical composition of AZ31B alloy (wt\%)

\begin{tabular}{ccccccc} 
Element & $\mathrm{Al}$ & $\mathrm{Zn}$ & $\mathrm{Mn}$ & $\mathrm{Si}$ & $\mathrm{Fe}$ & $\mathrm{Mg}$ \\
\hline Content & 3.22 & 1.15 & 0.40 & 0.0133 & 0.0019 & Bal. \\
\hline
\end{tabular}

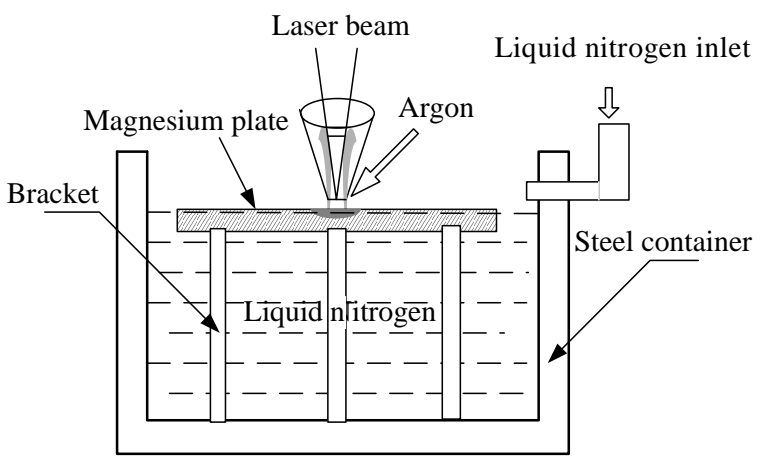

Fig.1 Schematic diagram of laser melting under extremely cooling circumstance
Table 2 Technical parameters of laser melting

\begin{tabular}{cccc}
\hline $\begin{array}{c}\text { Laser power/ } \\
\mathrm{W}\end{array}$ & $\begin{array}{c}\text { Scan speed/ } \\
\mathrm{mm} \cdot \mathrm{min}^{-1}\end{array}$ & $\begin{array}{c}\text { Spot diameter/ } \\
\mathrm{mm}\end{array}$ & $\begin{array}{c}\text { Gas flow rate/ } \\
\mathrm{L} \cdot \mathrm{min}^{-1}\end{array}$ \\
\hline 1500 & 240 & 3 & 15 \\
2000 & 240 & 3 & 15 \\
2500 & 240 & 3 & 15 \\
3000 & 240 & 3 & 15 \\
3500 & 240 & 3 & 15 \\
3000 & 180 & 3 & 15 \\
3000 & 240 & 3 & 15 \\
3000 & 300 & 3 & 15 \\
3000 & 360 & 3 & 15 \\
\hline
\end{tabular}

The laser melted sample was dissected along transverse section, then polished and etched using $0.4 \mathrm{~mL}$ nitric acid and $50 \mathrm{~mL}$ water solution for 5 6 s. Microstructure and phase constituents were examined by an optical microscope (CMM-20), the scanning electron microscope (JSM-6700F), and an X-ray diffractometer (Y-2000). Microhardness was measured by a Vickers microhardness tester (HVS-1000A) with a $50 \mathrm{mg}$ load and a $15 \mathrm{~s}$ dwell time. Wear resistance was measured by a reciprocating abrasion machine (MFT-R4000) with $500 \mathrm{~g}$ load, $20 \mathrm{~min}$ fraction time and $100 \mathrm{r} / \mathrm{min}$ rotational speed, and GCr15 was used as counter wearing specimen. A pendulum impact testing machine was used for impact study with impact energy of $4.8 \mathrm{~J}$ and testing temperature of $20{ }^{\circ} \mathrm{C}$, and the dimension of the specimen is shown in Fig.2.

\section{Results and Discussion}

\subsection{Microstructure of the melted layer far from equilibrium}

Initial microstructure of AZ31B magnesium (Fig.3) is coarse grain cellular with grain size about $50 \sim 200 \mu \mathrm{m}$. It is made up of $\alpha$ - $\mathrm{Mg}$ and a few $\beta-\mathrm{Mg}_{17} \mathrm{Al}_{12}$ distributed along grain boundaries. The original microstructure is obtained under equilibrium solidification and subsequent rolling. Under equilibrium solidification conditions, $\alpha-\mathrm{Mg}+\beta-\mathrm{Mg}_{17} \mathrm{Al}_{12}$ eutectics are formed first. Then, because there is a few eutectics, eutectics $\alpha$-Mg nucleat and grow attaching to primary $\alpha-\mathrm{Mg}$, and push $\beta-\mathrm{Mg}_{17} \mathrm{Al}_{12}$ to the grain boundaries of $\alpha-\mathrm{Mg}$, and then the divorced eutectics form.

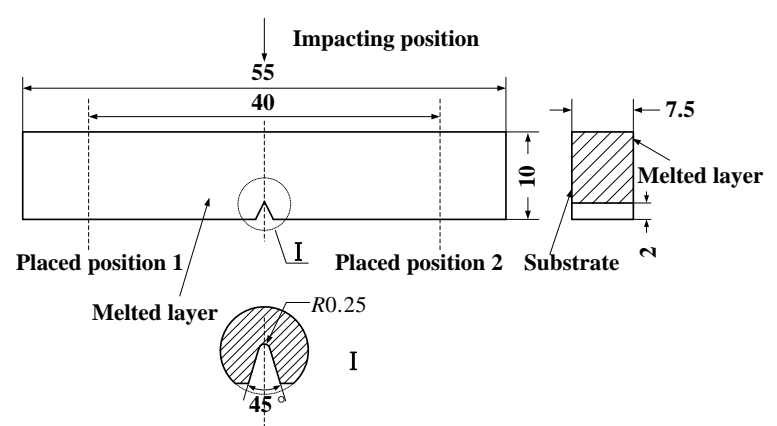

Fig.2 V type notch impact specimen (mm) 


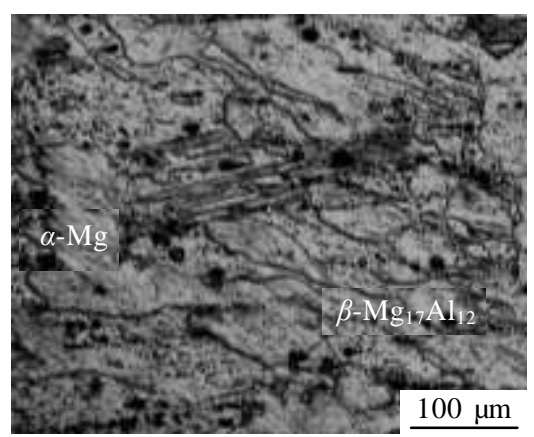

Fig.3 Microstructure of as-received AZ31B alloy

The experimental procedure in the present investigation was a dynamic fast cooling and rapid solidifying technique. And the rapid solidifying procedure, corresponding cooling and solidifying speed and solidified products are affected by factors such as melt capacity and heat transfer speed ${ }^{[8]}$. Under the extremely rapid cooling conditions, when material is solidifying, the temperature gradient is very high, and the solidification rate is very fast. So, the traditional solidification theory could not explain the solidification laws of the surface's material very well.

Fig.4 shows the microstructure of the melted layer obtained under extremely rapid cooling condition. It is interesting to note that crystals in the bottom of the melted layer (Fig.4a) grow upward, and their growing surface is the grains of un-melted substrate. Microstructure of lower part of the melted layer (Fig.4a) is columnar dendrites but not fir-tree crystals as mentioned in other researches ${ }^{[9,10]}$. The crystals in lower part continue to grow upward, and then slender columnar dendrites form. The crystals in the middle part (Fig.4b) grow upward. And in the upper part of the melted layer (Fig.4c), affected by the radiation of environment, the surface of molten pool heterogeneously nucleates and grows up. With coexistence of these two methods, microstructures of this region are finest. It could be further found that grains in the three regions are similar in size. Because the back of the specimen is immersed into liquid nitrogen before laser melting, and the melted layer is extremely rapidly cooled by liquid nitrogen during laser heating and cooling process when a little change occurs in the temperature gradient of these regions. It is different from the microstructure formed by the air cooling conditions, for the grain size of the melted layers is quite different ${ }^{[11,12]}$. Hence, in the present study, the undercooling of melt is higher. And finally the rapid solidified microstructures of the melted layer form.

Through the extremely rapid heating and cooling technique, more uniform and finer grains of the surface are formed as shown in Fig.5, and the grain size is $3 \sim 5 \mu \mathrm{m}$. The evolution of microstructure is attributed to the heat transfer in the middle of the melted layer and to the radiation of external environment. Moreover, non- equilibrium during laser melting causes great thermal stress, which makes the dislocation move. With the process, the dislocation motion increases, and the small angle sub-boundaries which are formed by dislocation accumulation zone gradually evolve into large angle grain boundaries, so the grains are refined obviously.

From Fig.6, it can be seen that $\beta-\mathrm{Mg}_{17} \mathrm{Al}_{12}$ distributed along the grain boundaries are less under non-equilibrium solidification conditions.

Fig.7 shows the interface of the melted layer's surface and the substrate. Different from Fig.4a, the more uniform grains are formed. Mainly affected by substrate radiating, the melt nucleates and grows up as shown in Fig.4. Both the substrate and the environment radiation affected the surface of the melt. Moreover, as shown in Fig.8, the content of main elements such as $\mathrm{Mg}$ and $\mathrm{Al}$ in the surface of the melted layer and the substrate is almost the same. The technique in this study just re-melts and solidifies the surface of magnesium alloy, but it does not change the composition.

\subsection{Phase composition}

From XRD (Fig.9), it could be seen that the substrate is mainly consisted of $\alpha-\mathrm{Mg}$ and $\beta-\mathrm{Mg}_{17} \mathrm{Al}_{12}$. But the melted

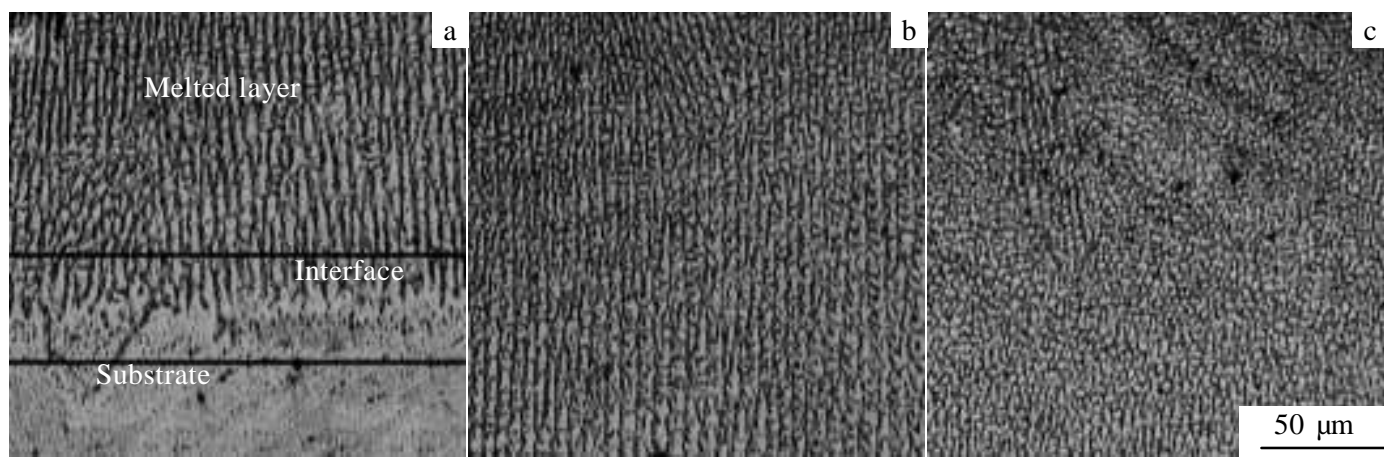

Fig.4 Microstructures of laser melted layer: (a) interface between melted layer and substrate, (b) middle of melted layer, and (c) upper part of melted layer 


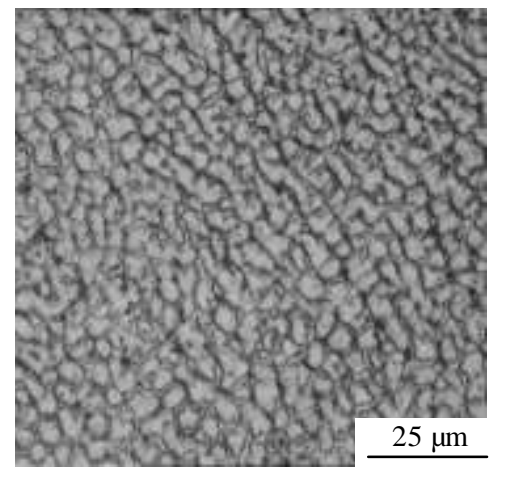

Fig.5 Microstructure of melted layer's surface

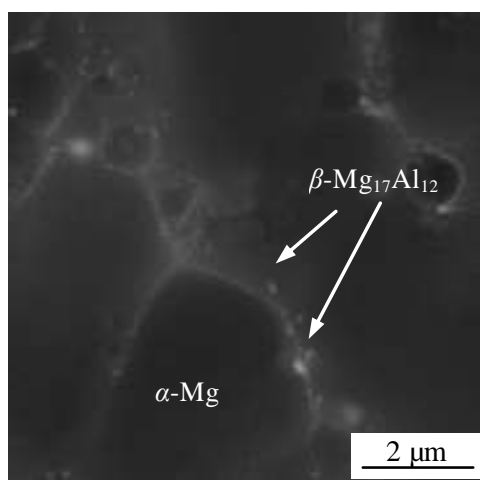

Fig.6 Further amplification of grains of melted layer

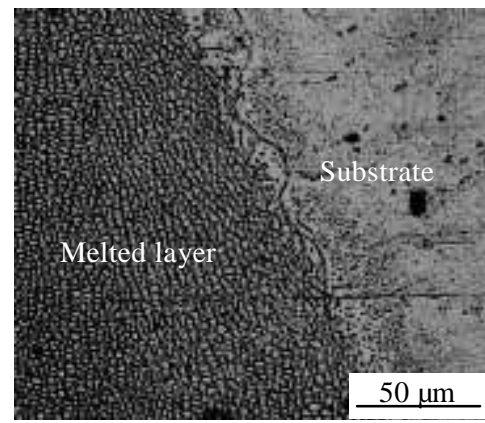

Fig.7 Interface between melted layer and substrate on the surface of the sample

layer is almost $\alpha-\mathrm{Mg}$, and the diffraction peak of $\alpha-\mathrm{Mg}$ moves slightly to the right.

During the laser melting, owing to the rapid cooling rate and non-equilibrium solidification, the solid solubility of the solute is greater than that obtained under equilibrium solidification, so $\alpha-\mathrm{Mg}$ solid solution with more supersaturation is formed. Because $\beta-\mathrm{Mg}_{17} \mathrm{Al}_{12}$ of a smaller size (Fig.6) decomposes and dissolves, $\alpha$-Mg formes. ${ }^{[13]}$ Furthermore, according to the literatures, some elements whose atomic radius were in the range of $\pm 15 \%$ would solve into $\alpha-\mathrm{Mg}$ increasingly by the rapid solidification technique $^{[7]}$. Therefore, under the extremely rapid cooling condition, $\alpha-\mathrm{Mg}$ dissolves a large number of $\mathrm{Al}$ and $\mathrm{Zn}$

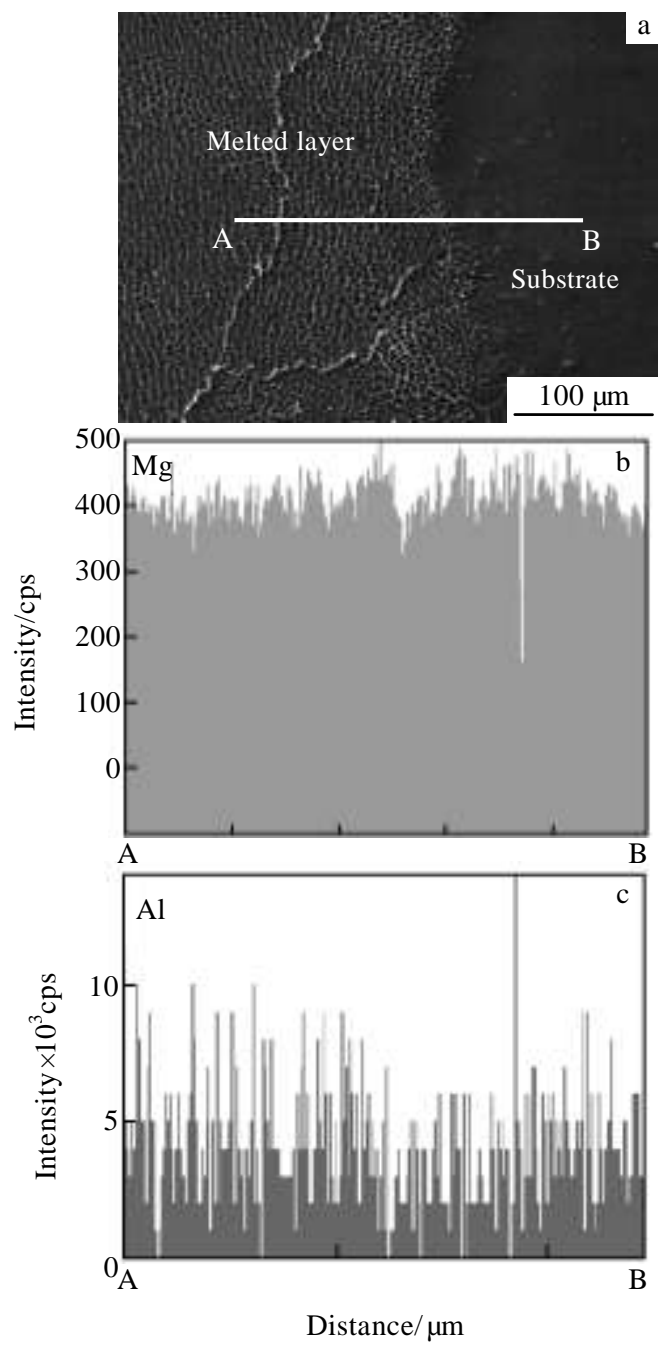

Fig.8 Surface morphology (a) of the melted layer and distribution of $\mathrm{Mg}(\mathrm{b})$ and $\mathrm{Al}(\mathrm{c})$ elements

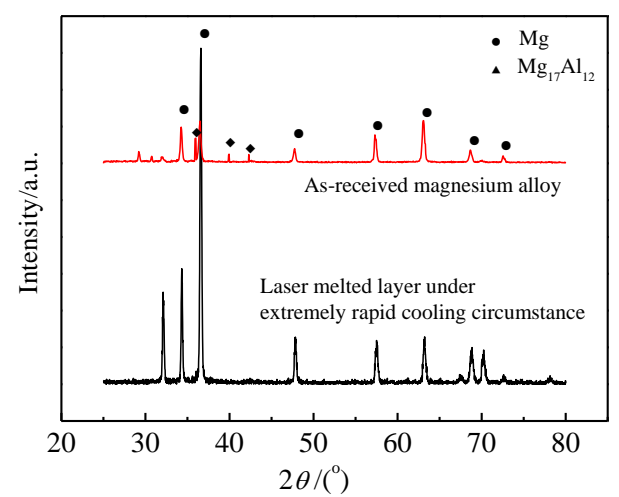

Fig.9 XRD patterns of as-received magnesium alloy and melted layer

whose the atomic radius were much smaller ${ }^{[14]}$, and hence the diffraction peak shifted. It is illustrated that the extremely rapid cooling condition caused by laser and liquid nitrogen could hinder the diffusion and migration of 
solute atoms. Thus, supersaturated single phase $\alpha-\mathrm{Mg}$ solid solution formed and grows fast. Consequently, the eutectic transformation of $\mathrm{L} \rightarrow \alpha-\mathrm{Mg}+\beta-\mathrm{Mg}_{17} \mathrm{Al}_{12}$ occurring under the equilibrium state is inhibited.

\subsection{Performance of melted layer}

Fig.10 shows the microhardness HV of the melted layer. It reveals that microhardness of the melted layer (about $1400 \mathrm{MPa}$ ) cooled under extremely rapid cooling condition, i.e. cooled under liquid nitrogen, has significantly increased by about 2.8 times as compared to that of the substrate (about $500 \mathrm{MPa}$ ). Moreover, it is higher than the microhardness of melted layer cooled in air.

Fig.11 shows the wear morphology of the melted layer with extremely rapid cooling rate. There are almost no furrows or wearing spinals on the abrasive surface (Fig.11a), but some apparent oxides (Fig.11b) appear. It could be explained by the following reasons. The temperature of materials rises during rubbing, and surface oxidation is prone to occur in the atmospheric environment. It plays an important role in friction resistace. Since more refined grains of the melted layer result in a denser oxide film during wearing process, the oxide film could delay wear process.

The wear data of the substrate and the melted layer of magnesium alloy is listed in Table 3. It shows that the technique in the present study has greatly improved wear resistance of the surface of AZ31B.

Fig.12 shows the impact fracture of laser melted layer at room temperature. The melted layer exhibits a little plastic deformation (Fig.12b), because there are some features of tough dimples and some traces of grain pulled out. But the substrate (Fig.12c) displays brittle fracture with sensible cleavage steps and cracks.

\subsection{Strengthening mechanisms}

Far from equilibrium solidification state caused by the extremely rapid cooling condition in this study can not only improve microhardness and wear resistance of melted layer, but also can improve the plasticity and ductility. It could be explained by the following reasons.

The refined grains play an important role. According to Hall-Petch equation, the smaller the grain size is, the higher

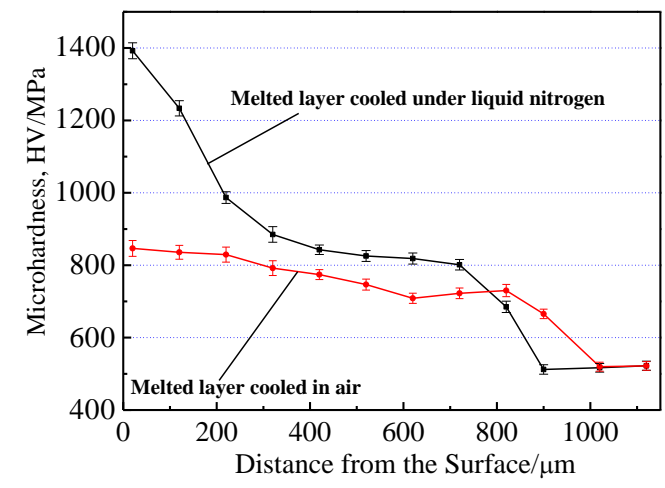

Fig.10 Microhardness of melted layer

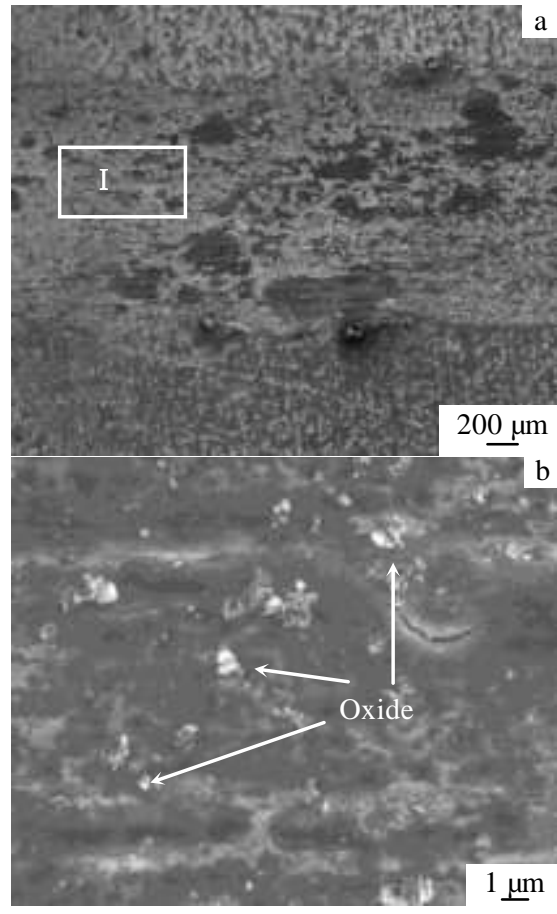

Fig.11 Wear morphologies of laser melted layer (a) and magnified view of I region (b)

Table 3 Wear data of substrate and melted layer

\begin{tabular}{|c|c|c|c|}
\hline Item & Substrate & $\begin{array}{c}\text { Melted layer } \\
\text { (cooled in liquid } \\
\text { nitrogen) }\end{array}$ & $\begin{array}{l}\text { Melted layer } \\
\text { (cooled in air) }\end{array}$ \\
\hline Wear loss/mg & 10 & 5 & 8 \\
\hline $\begin{array}{l}\text { Highest } \\
\text { friction } \\
\text { coefficient }\end{array}$ & 0.323 & 0.261 & 0.312 \\
\hline $\begin{array}{l}\text { Average } \\
\text { friction } \\
\text { coefficient }\end{array}$ & 0.217 & 0.168 & 0.200 \\
\hline
\end{tabular}

the hardness value is. This illustrats that grain refinement in the melted layer which is treated under extremely rapid cooling rate results in the increment of microhardness. In addition, the decreased amount of wear is due to the increased microhardness of the melted surface.

The dislocation takes effect. As shown in Fig.13a, there are a few dislocations in some areas of as-received AZ31B alloy. And the dislocation density is higher in the melted layer as shown in Fig.13b. In addition, grains refinement appears at extremely low temperature, and at this temperature thermal vibration energy of crystal lattice decreases. Thus, the microhardness of the melted layer cooled under extremely cooling condition is improved.

The super-solid solution is at work. As previously stated, the phase of the melted layer obtained under extremely rapid cooling condition is almost $\alpha-\mathrm{Mg}$, but there is 

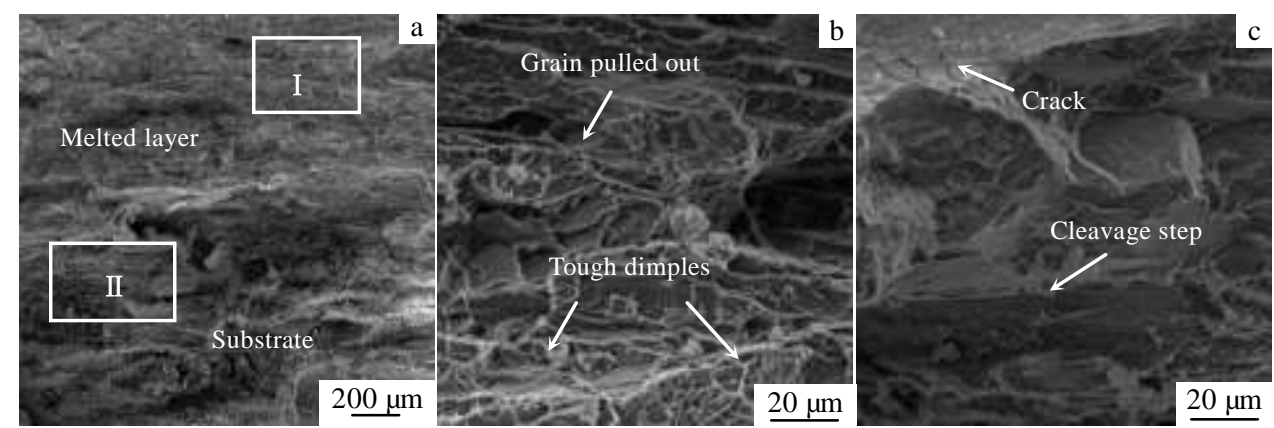

Fig.12 Impact fracture morphologies of melted layer (a); magnified view of I region (b) and II region (c)

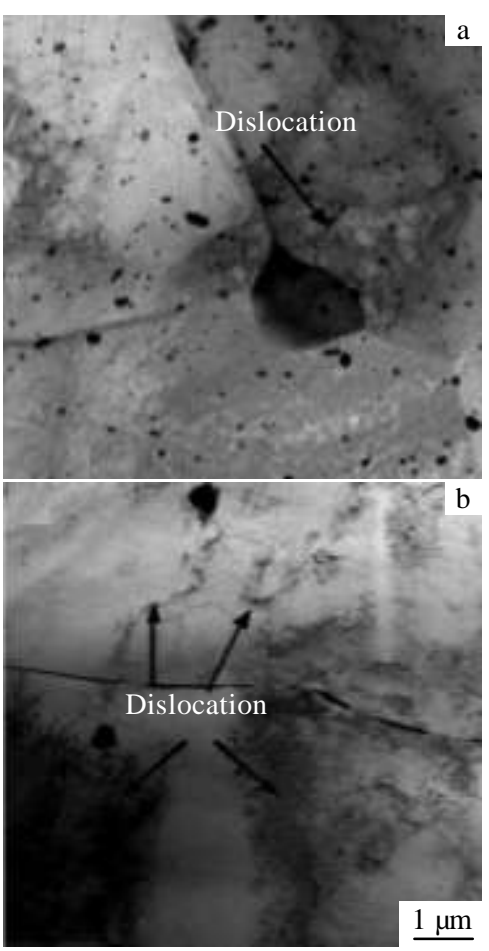

Fig.13 Local dislocations of as-received AZ31B alloy (a) and laser melted layer (b)

little $\beta-\mathrm{Mg}_{17} \mathrm{Al}_{12}$ in the melted layer. These illustrate that in the melted layer a large amount of $\mathrm{Al}$ element dissolves into $\alpha-\mathrm{Mg}$, and it could introduce distortion of lattice. That may increase the resistance to dislocation motion.

\section{Conclusions}

1) By laser surface melting on AZ31B under the extremely cooling circumstance, a melted layer without defects is obtained.

2) Continued cooling in liquid nitrogen, extremely rapid solidification structure far from equilibrium is obtained, and grain size is nearly uniform. Because $\alpha-\mathrm{Mg}$ dissolved a large number of $\mathrm{Al}, \mathrm{Zn}$, etc., the melted layer is almost composed of $\alpha-\mathrm{Mg}$, but $\beta-\mathrm{Mg}_{17} \mathrm{Al}_{12}$ is little.

3) Microhardness of the melted layer is significantly increased by about 2.8 times. Wear resistance of the melted layer is improved obviously. Impacting fracture morphology indicates that the plastic deformation appears, and the plasticity and ductility are also improved.

4) Strengthening mechanism of the melted layer is mainly grain refinement. Besides, dislocation and super solid solution also take effect in strengthening.

\section{References}

1 Chen Zhenhua. Magnesium Alloy[M]. Beijing: Chemical Industry Press, 2004 (in Chinese)

2 Gao Yali, Wang Cunshan, Xiong Dangsheng et al. Transactions of Materials and Heat Treatment[J], 2009, 30: 146 (in Chinese)

3 Qian Jiangang, Zhang Jiaxiang, Li Shuqing et al. Rare Metal Materials and Engineering[J], 2012, 41(2): 360 (in Chinese)

4 Hazra M, Mondal A K, Kumar S et al. Surface and Coating Technology[J], 2009, 203: 2292

5 Bernabe Carcel, Jesus Sampedro, Ana Ruescas et al. Physics Procedia[J], 2011, 12: 353

6 Zhang Weiping, Liu Shuo. Foundry[J], 2005, 54: 28

7 Yu Kun, Li Wenxian, Wang Richu et al. Chinese Journal of Nonferrous Metals [J], 2007, 17: 1025 (in Chinese)

8 Zhou Shuhe, Liu Ming, Sun Zhanhong et al. Friend of Science Amateurs[J], 2009, 14: 29 (in Chinese)

9 Wei Zhongshan, Liu Liufa. Special Casting and Nonferrous Alloys[J], 2011, 31: 507 (in Chinese)

10 Ghazanfar Abbas, Lin Li, Uzma Ghazanfar et al. Wear[J], 2006, 260: 175

11 Walid Khalfaoui, Eric Valerio, Jean Eric Masse et al. Optics and Lasers in Engineering[J], 2010, 48: 926

12 Gao Yali, Wang Cunshan, Liu Hongbin et al. Chinese Journal of Lasers[J], 2007, 34: 1019 (in Chinese)

13 Cui Hongzhi, Xiao Chengzhu, Sun Jinquan et al. Chinese Journal of Nonferrous Metals[J], 2012, 22: 1000 (in Chinese)

$14 \mathrm{Xu}$ Jinfeng, Zhai Qiuya. Rare Metal Materials and Engineering $[\mathrm{J}], 2004,33(8)$ : 835 (in Chinese) 


\title{
远离平衡态下镁合金表面激光重熔强化的研究
}

\author{
葛亚琼 ${ }^{1,2}$, 王文先 ${ }^{1,3}$, 郭 谡 $^{1}$, 崔泽琴 ${ }^{1,3}$ \\ (1. 太原理工大学, 山西 太原 030024) \\ (2. 太原科技大学, 山西 太原 030024)
}

(3. 新材料界面科学与工程教育部重点实验室, 山西 太原 030024)

\begin{abstract}
摘 要: 为了在镁合金表面获得远离平衡态的极端快速冷却结构, 对 $A Z 31 \mathrm{~B}$ 镁合金进行了在液氮环境下极端快速冷却的 $\mathrm{CO}_{2}$ 激光表面重 熔处理, 并对该重熔层的微观结构、性能和强化机制进行了分析研究。结果表明: 远离平衡态结晶凝固的镁合金表面重熔层的晶粒高度 细化, 且晶粒大小基本均一。重熔层主要为 $\alpha-\mathrm{Mg}$, 以及沿晶界析出的极少量 $\beta-\mathrm{Mg}_{17} \mathrm{Al}_{12}$ 。极端快速冷却条件获得的远离平衡态的重熔层 的强化机制主要为细晶强化、超固溶强化和位错强化。在此强化作用下重熔层的显微硬度HV提高到 $1400 \mathrm{MPa}$, 磨损失量比空气冷却条 件下的少 $50 \%$, 耐磨性显著提高。该重熔层的冲击断口特征显示出了塑性变形的痕迹, 故该镁合金表面的塑性和㓞性也得到了改善。 关键词: 镁合金; 激光重熔; 非平衡; 组织; 性能
\end{abstract}

作者简介: 葛亚琼, 女, 1982 年生, 博士, 讲师, 太原理工大学材料科学与工程学院, 山西 太原 030024, E-mail: joan1028@163.com 